\title{
El Apocalipsis, memoria subversiva y fuente de esperanza para los pueblos crucificados (II)
}

\section{Xavier Alegre, \\ Facultad de Teología de Cataluña, \\ Centro de Reflexión Teológica, San Salvador.}

\section{La estructura del Apocalipsis}

Se ha notado, con razón, que ningún otro libro apocalíptico está tan claramente estructurado como el Apocalipsis ${ }^{*}$. Como vamos a ver, hay demasiados indicios en el texto que quieren revelar una estructura muy consciente, como para que podamos poner en duda que Juan quiso damos con ello una pista de lectura fundamental que nos ayude a descubrir cómo quiere él que leamos su obra. En este sentido resulta decisivo para una adecuada interpretación del Apocalipsis que procuremos descubrir cuál es la estructura que el autor quiso darle, pues ello nos ayudará a ver el todo desde el cual hay que leer cada una de las partes (el todo está siempre antes que las partes).

Pero al abordar esta tarea nos encontramos con una dificultad fundamental. A juzgar por la diversidad de estructuras que han propuesto los especialistas, la estructura no parece, a primera vista por lo menos, evidente ${ }^{57}$. ¿Cómo descubrir, entonces, cuál pudo ser la estructura que Juan quiso dar a su obra?

Para tener más garantía de objetividad, la respuesta debe conjugar dos tipos de elementos: los literarios y los de contenido. Pues sólo si se complementan tendremos una cierta garantía de que responden a la intención del autor.

\section{Elementos literarios}

El autor nos da en Apocalipsis una serie de pistas literarias que resaltan claramente $^{50}$. Destacaré sólo algunas de ellas que me parecen más fundamentales.

En primer lugar, wodos los comentaristas están de acuerdo en que tanto la introducción (Ap 1, 1-8) como la conclusión (Ap 22, 6-21) están Cormuladas, conscientemente, de modo paralelo (los mismos temas resuenan en una y otra). De esta manera queda claro que forman una inclusión que enmarca toda la 
En este artículo hemos usado la métafora del viento para orientar nuestra reflexión. Siguiendo la metáfora podemos concluir diciendo que Santo Domingo no ha sido ciertamente un vendaval, como "la rálaga de viento impetuoso" de pentccostés. Visto todo en su conjunto, vivimos en una Iglesia en la que, después de que el concilio abriera sus ventanas, éstas se eslán volviendo a ccrrar y el aire se ha vuelto a enrarecer. Pcro en Santo Domingo y, sobre todo, en la realidad cotidiana de las iglesias latinoamericanas persiste, digamos, la brisa de Medellín, simbolizada en la Secunda Relatio. Y en muchos momentos de compromiso y esperanza, sobre todo los martiriales, esa brisa se convierte en venda$\mathrm{val}$, y en cualquier caso, contra viento y marea, muchos siguen adclante.

No es por terminar rutinariamente ni por hacer de la necesidad virtud, decir entonces que está en manos de la Iglesia latinoamericana poner a producir lo mejor del acontecimiento de Santo Domingo y de sus textos. Y no lo es porque, como hemos tratado de exponer, allá soplaron muchos y variados vientos, y también vientos positivos. Si con tantos poderes en su contra, políticos, cconómicos, culturales, militares, religiosos, a veces también eclesiales, hay cristianos que siguen caminando según la nueva identidad de la Iglesia, según el espíritu de Medellín, entonces es que el Espíritu de Jesús y el Espíritu de Dios siguen actuando. Y con ese Espírilu se pucde scguir adelante. 


\section{El Apocalipsis, memoria subversiva y fuente de esperanza para los pueblos crucificados (II)}

\section{Xavier Alegre, \\ Facultad de Teología de Cataluña, \\ Centro de Reflexión Teológica, San Salvador.}

\section{La estructura del Apocalipsis}

Se ha notado, con razón, que ningún otro libro apocalíptico está tan claramente estructurado como el Apocalipsis ${ }^{6}$. Como vamos a ver, hay demasiados indicios en el texto que quieren revelar una estructura muy consciente, como para que podamos poner en duda que Juan quiso damos con ello una pista de lectura fundamental que nos ayude a descubrir cómo quiere él que leamos su obra. En este sentido resulta decisivo para una adecuada interpretación del Apocalipsis que procuremos descubrir cuál es la estructura que el autor quiso darle, pues ello nos ayudará a ver el todo desde el cual hay que leer cada una de las partes (el todo estú siempre antes que las partes).

Pero al abordar esta tarea nos encontramos con una dificultad fundamental. A juzgar por la diversidad de estructuras que han propuesto los especialistas, la estructura no parece, a primera vista por lo menos, evidente ${ }^{57}$. ¿Cómo descubrir, entonces, cuál pudo ser la estructura que Juan quiso dar a su obra?

Para tener más garantía de objetividad, la respuesta debe conjugar dos lipos de elementos: los literarios y los de contenido. Pues sólo si se complementan tendremos una cierta garantía de que responden a la intención del autor.

\section{Elementos literarios}

El autor nos da en Apocalipsis una serie de pistas literarias que resaltan claramentes ${ }^{38}$. Destacaré sólo algunas de ellas que me parecen más fundamentales.

En primer lugar, todos los comentaristas están de acuerdo en que tanto la introducción (Ap 1, 1-8) como la conclusión (Ap 22, 6-21) están formuladas, conscientemente, de modo paralelo (los mismos temas resuenan en una y otra). De esta manera queda claro que forman una inclusión que enmarca coda la 
obra". Con ello Juan nos da un primer indicio que subraya no sólo la unidad de la obra, sino también su posible estructura concéntrica. En la misma línea hay que colocar también el hecho de que tanto el primer como el último septenario del Apocalipis estén estructurados, a su vez, también concéntricamente, como varmos a ver luego.

En segundo lugar, hay coincidencia también entre los especialistas a propósito del hecho de que por lo menos una parte notable del Apocalipsis está estructurada en forma de septenarios ${ }^{\omega 0}$. Pues el autor lo indica explícitamente al menos en cuatro bloques lundamentales de su obra, cuando presenta el contenido de lo que vio y oyó en forma de siete carlas (Ap 2-3), siete sellos $(5,2-8,1)$, siele trompctas $(8,2-11,15 a)$ y sietc copas $(15,5-16,21)$. Si esto es así, podemos sospechar, entonces, con fundamento que, aunque Juan no lo indique explícitamente, también la última parte del Apocalipsis esté estructurada en forma de siete visiones. Y de hecho es así. Pues Apocalipsis 19,11-22, 5 contiene cabalmente sicte visiones, cada una de las cuales comienza con la formula kai eidon ("Y vi")". Con ello toda la obra estaría cstructurada en scptenarios. Y no sería objeción que el autor no numere las siete visiones (a diferencia de lo que ocurre en los septenarios centrales), pues el primer septenario, el de las cartas, que sí cslá presentado ciertamente en forma de septenario (véase Ap l, 11 y 20) y que formaría inclusión con el último septenario, tampoco numera cada una de las cartas.

En tercer lugar, resulta también patente -y en ello concuerdan también los comentaristas - que los septenarios segundo (de los sellos), tercero (de las trompetas) y cuarto (de las copas) están concatenados entrc sí y están construídos con un cierto paralclismo. En las claras alusiones a las plagas de Egipto que encontramos en cada una de las trompelas y de las copas de los scpienarios tercero y cuarto, el paralelismo es evidente ${ }^{62}$. Pero no se tata de un paralelismo absolutamente estricto, por cuanto se da también, claramente, un progreso denvo de los tres septenarios ${ }^{63}$. Lo mostraré en dos ejemplos concretos. En primer lugar, Juan tiene interés en que descubramos que el castigo que anuncian es cada vez más grave. Pues si en el scptenario segundo se anuncia que una cuarta parte será destruída (véase Ap 6,8), en el tercero se destruye ya una tercera parte (véase Ap 8,7-12, 15) y en el cuarto se proclama la destrucción total (véase Ap 16). En el mismo sentido conviene notar, en segundo lugar, que tanto el séptimo sello del segundo septenario, como la sćptima trompeta del tercero no son descritos, como se esperaria después de la descripción de los otros sellos y urompetas que encontramos en los septenarios respectivos. Juan menciona tan sólo que se abre el séptimo scllo (véase Ap 8,1) o que sucna la séptima trompe-

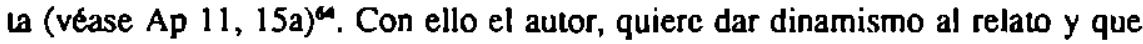
el lector caiga en la cuenta de que hay un progreso en cl relato y que sin la lectura del siguiente septenario no se puede comprender, a cabalidad, el significado del segundo y yerfer septenarios se "P. Florentino Idoate, S.J."

Universidad Centroamericana José Simeón Cañas 
En cuarto lugar, es especílico también del Apocalipsis que el autor vaya intercalando, sobre todo en el septenario central, unos textos que parecen como retardar el último momento del septenario (que en los tres septenarios centrales apunta sicmpre al futuro que está esperando la comunidad, me refiero a la caída de Roma), de modo que algunos la han interpretado como una manera sutil de ayudar a la comunidad a asimilar el escándalo del retraso de la parusía". le permiten también, por otro lado, desarrollar aquellas ideas teológicas nucleares que ayudan a desentrañar el sentido último de lo que está ocurriendo en el mundo.

En quinto lugar, conviene también que descubramos que a lo largo de toda la obra hay una scric de motivos, que se van repitiendo en los distintos septenarios, y de referencias literarias cruzadas que subrayan la concatenación de los distintos fragmentos. En este sentido, los motivos del árbol de la vida que está en el Paraíso (véase Ap 2, 9 y 22,2), de la segunda muerte (Ap 2, 11 y 20, 14; 21, 8), del nombre nuevo que nadic conocc (Ap 2, 17 y 19,12), del celro de hierro con que Cristo regirá a las naciones (Ap 2, 26-27 y 19, 15), del libro de la vida (Ap 3,15 y 20, 12), de la nucva Jerusalén bajada del ciclo (Ap 3, 12 y 21, 2-3) o del sentarse con Cristo en el trono (Ap 3,21 y 20,4) son motivos que aparecen en el primer y en el último septenario, confirmando la tesis de que la estruclura del Apocalipsis es, conscientemente, concéntrica. Aparte de los motivos que van repitiéndose a lo largo del Apocalipsis, mostrando la concatenación entre los distintos septenarios (por ejemplo, el motivo de las bodas del Cordero y de la esposa engalanada que sucna al final del cuarto septenario - véase Ap 19, 7-8es desartollado en Ap 21, 2 en la última visión del quinto septenario), conviene notar también las referencias cruzadas que muestran la trabazón interna de la obra. Por ejemplo, los tres ;Ayes! que son enunciados en 8, 3 indicándose en 9 , 12 y ll, 14 (véase también 18, 10.16.19) cómo van pasando. $O$ las tres ocasiones en que se constata que aparece en el cielo "una gran señal" (véase Ap 12, 1; 12, 3 y 15,1 ).

En sexto lugar, quisiera destacar algo en lo que coinciden también todos los comentaristas, pues resulta evidente: todas las cartas del primer septenario están construidas según un modelo estereotipado, que se va repitiendo con ligeras variantes y de acuerdo con una estructura concéntrica ${ }^{\text {t6 }}$.

Por último, y para no alargarme más sobre eslos aspectos literarios, quisiera notar que Charlier" ha puesto de manifiesto, a mi juicio con razón, que cada uno de los cinco septenarios que conliguran ahora el Apocalipsis está estructurado en tres partes: a) una visión preparatoria que introduce el septenario, b) un núcleo central que contiene el septenario en cuestión, y c) una liturgia en el cielo con que concluye el septenario, - a excepción del último septenario, que acaba sin liturgia explícita, pues en la Jerusalén celestial no hay ya ni templo ni altar "porque el Señor, Dios Todopoderoso, y el Cordero, es su Santuario" (Ap

Digitalizado por Biblioteca "P. Florentino Idoate, S.J."

Universidad Centroamericana José Simeón Cañas 
$21,22)$.

De lo que acabo de decir se deduce que la cstructura que mejor responde a la intención del autor es, en mi opinión, la estruclura concéntrica en cinco septenarios que propone Charliers. Se ha objetado a las estructuras concéntricas que no dan razón suficientemente del progreso lineal que, sin duda, se da también en cl Apocalipsis ${ }^{69}$. Pero la objeción no es pertinaz. Pues la estructura que proponemos permile descubrir también el progreso lineal y es la que mejor da razón de dos aspectos que el Apocalipsis quiere subrayar.

a) Por un lado, Juan quiere destacar la lidelidad de Dios que, de modo regular, actúa liberadoramente en la historia en favor de su pucblo empobrecido y humillado por los poderes del mal que, regularmente tambićn, quicren destruir los valores propios de la fe, judía primero y cristiana después. En este sentido, las estructuras concénuricas, a la vez que dan razón de la unidad interna de determinados septenarios (el primero y el último), revelan la unidad global de la obra y, junto con el paralclismo de los septenarios centrales, ponen de manifiesto esta regularidad con que Dios se revela en la historia. Pues muestran el estilo de la actuación del Dios fiel en el mundo, revelando así en la historia el verdadero rostro de Dios y poniendo de manifiesto que el verdadero Señor del mundo y de la historia es y sigue siendo El, por lo que lo será también en el futuro. Por eso el Apocalipsis no se cansa de denominar a Dios (iy sólo a Dios!) el Todopoderoso (véase Ap 1,$8 ; 4,8 ; 11,17 ; 15,3 ; 16,7.14 ; 19,15 ; 21,22$ ) o de circunscribir su nombre (recordando el nombre de Yahvé de Ex 3,14) con las palabras "cl que es, que era y que va a venir" (Ap 1, 4.8; 4, 8; cf. también 11, 17 y 16,5 , donde ya no se dice "el que va a venir", pues se supone, a partir del toque de la séptima trompeta en 11, 15a, que ha venido ya al mundo a asumir su reinado).

b) Y, por otro lado, la concatenación y progreso dentro de los distintos septenarios mucstra la segunda preocupación fundamental de Juan. Revelar que en el mundo no se da un etcrno relomo de todas las cosas (eso llevaría al desánimo de la comunidad), sino un auténtico progreso de la historia que se va acercando al momento en que Dios lo será todo en lodos. Por ello lodo el Apocalipsis se encamina, en su dinamismo interno, hacia el Dios-con-nosotros (prometido ya por Is 7,14 ): "Pondrá su morada entre ellos y ellos serán su pueblo y él, Dios-con-ellos, será su Dios" (Ap 21, 4). Este final, con todo, no será un mero restablecimiento del paraíso perdido ni de la vieja Jerusalén amada, sino nueva creación que superará, con creces, las expectativas del pueblo creyente. Con todo, el autor tiene también mucho interés en insistir (y la estructura de la obra lo muestra) que desde que Dios entró en el mundo con Jesús de Nazaret, el primer mártir, a quien Dios exaltó a su diestra (véase Ap 5,$1 ; 12,5$ ), esta nueva creación no es algo meramente futuro o celestial, sino que está ya operando en la tierra. Desde entonces, Satanís ha perdido ya la capacidad de acabar con la Digitalizado por Biblioteca "P. Florentino Idoate, S.J."

Universidad Centroamericana José Simeón Cañas 
comunidad cristiana (véasc Ap 12), que participa ya, aquí y ahora, del reinado de Cristo, como indica Juan en Apocalipsis 20,6.

\section{Elementos de contenido}

Estos elementos, que confirman la cstructura litcraria que proponemos, han ido aparcciendo ya a medida que examinábamos los clementos literarios del Apocalipsis. Pcro me detendré un poco en este punto porque a menudo se ha objetado quc, por el contenido, resule necesario separar claramente dos bloques cn el Apocalipsis, Ilegándose, incluso, a sostener que, por cjemplo, el fragmento de las carlas pudiera haber sido añadido en una scgunda edición del Apocalipsis $^{70}$. Pero, a mi juicio, cl texto actual no lavorece una scparación entre cl septenario de las carlas y el resto de la obra ni una estruclura que separe en dos bloques fundarnentales (de los capítulos 4 al 11 y del 12 al 22) la parte nuclear de la obra.

En primer lugar porque, como ya vimos, el hecho de que en el texto actual la introducción (Ap 1, 1-8) y el epilogo (Ap 22, 6-21) formen una inclusión que enmarca claramente toda la obra, parece indicar que cl autor desea que leamos todo el Apocalipsis como formando una unidad lundamental, de modo que no podamos separar el septenario de las cartas del resto del Apocalipsis.

Esto viene confirmado, en segundo lugar, por lo que Juan nos dice en Apocalipsis 1,19 (véase también 4,1) en la introducción al septenario de las cartas. Pues si en este texto el vidente recibc la orden "cscribe, pues, lo que has visto: lo que ya es y lo que va a suceder más tarde", reliriéndose, evidentemente, con la expresión "lo que va a suceder más tardc" a las visiones que aparecen después del septenario de las cartas, es que Juan concibe su obra, por lo menos en su redacción final, que es la inspirada, como formando una unidad global" ${ }^{71}$. Más aún, si el autor ha colocado conscientemente el septenario de las cartas al comienzo de su obra, ello se deberá a que con ello quiere orientar adecuadamente la lectura de toda la obra, de modo que el oyente lea las siguientes visiones del Apocalipsis en función de lo que Juan le está diciendo a sus iglesias en el momento actual, evitando así lecturas apocalipticistas (como si fueran especula. ciones sobre el fin del mundo) que desfigurarían lo nuclear del mensaje.

Por último, y para no alargarme más en este punto, la descripción, en el primer septenario, de la Iglesia militante de su tiempo y la exhortación que le dirige Juan a que sea digna de la vocación martirial que ha recibido está apuntando hacia la realidad de la Iglesia triunfante, presentada en el último septenario de la obra. Con ello, el autor nos está invitando a leer la parte central de su obra como un ejercicio de discemimiento cristiano que nos ayude a descubrir cómo se pasa, de acuerdo con el plan providente y misericordioso de Dios, de la Iglesia militante a la Iglesia triunfante, y eso en medio de un mundo que parece dominado por las fuerzas del mal que han desencadenado una guerra encarniza-
Digitalizado por Biblioteca "P. Florentino Idoate, S.J."

Universidad Centroamericana José Simeón Cañas 
da contra los seguidores del Cordero degollado (véase Ap 12, 12b).

Vcamos, pues, la estructura global del Apocalipsis para, en un segundo paso, detenemos brevemente en el significado de cada una de sus partes.

\section{Estructura}

Prólogo y saludo epistolar (1, 1-3. 4-8)

A. Primer septenario: las siete cartas $(1,9-4,11)$ :

la Iglesia militante

Visión preparatoria $(1,9-20)$

Septenario $(2,1-3,22)$

Carta a Efeso $(2,1-7)$

Carta a Esmima $(2,8-11)$

Carta a Pérgamo $(2,12-17)$

Carta a Tiatira $(2,18-29)$

Carta a Sardes $(3,1-6)$

Carta a Filadelfia $(3,7 \cdot 13)$

Carta a Laodicea (3, 14-22)

Liturgia final en el cielo $(4,1-11)$

B. Segundo septenario: los siete sellos $(5,1-8,1)$ :

la historia re (=des) velada

Visión preparatoria $(5,1-14)$

Septenario $(6,1-7,8)$

Cuatro primeros sellos $(6,1-8)$ : los cuatro jinetes (plagas que amenazan)

Quinto sello $(6,9-11)$ : los mártires claman venganza

Sexto sello $(6,12-17)$ : señales apocalípticas de la ira de Dios

Intermedio (7, 1-8): los elegidos, sellados antes del castigo

Liturgia final en el cielo (7, 9-17)

Apertura del séptimo sello $(8,1)$

C. Tercer septenario: las siete trompetas $(8,2-14,5)$ :

la fe pascual movilizada

Visión preparaloria $(8,2-5)$

Septenario $(8,6-13,18)$

Introducción $(8,6)$

Cuatro primeras trompetas $(8,7-12)$ : sobre tierra, mar, aguas dulces, sol

Anuncio de los tres jayes! $(8,13)$

Quinta trompeta $(9,1-11)$ : sobre los hombres incredulos

El primer ay ha pasado $(9,12)$

Sexta trompeta $(9,13-21)$ : sobre el Eulrates

Digitalizado por Biblioteca "P. Florentino Idoate, S.J."

Universidad Centroamericana José Simeón Cañas 
Primer gran intermedio $(10,1-11,13)$

Vocación profética de Juan (10, 1-11)

Misión profética de los cristianos (11, 1-13)

El segundo ay ha pasado $(11,14)$

Anuncio de la séptima trompeta $(11,15 a)$

Cántico en el cielo (Arca de la Alianza) $(11,15 b-18)$

Segundo gran intermedio $(12,1-13,18)$

La lucha entre el pueblo de Dios y el Dragón (12)

Los aliados del Dragón: las dos Bestias (13)

Liturgia final en el cielo (14, 1-5)

B'. Cuarto septenario: las siete copas $(14,6-19,8)$ :

la ira de Dios revelada en la historia

Visión preparatoria $(14,6-20)$

Septenario $(15,1-18,24)$

Introducción $(15,1-8)$

Cuatro primeras copas (16, 1-9): sobre tierra, mar, aguas dulces, sol

Quinta copa (16, 10-11): sobre el trono de la Bestia (Imperio)

Sexta copa $(16,12-16)$ : sobre el Eufrates

Séptima copa (16, 17-21): Caída de la gran Babilonia

Descripción e identificación de Babilonia, la gran ramera:

Roma (17)

Canto por la caída de Babilonia (18): tres ayes (vv. 10.16.19)

Liturgia final en el cielo $(19,1-8)$

A'. Quinto septenario: las siete visiones $(19,9-22,5)$ :

la victoria (final)

Introducción $(19,9-10)$

Septenario $(19,11-22,5)$

Aparición del Mesías como jucz y guerrero victorioso (19, 11-16)

Anuncio de la victoria $(19,17-18)$

Primer combate escatológico (19, 19-21): derrota de los aliados del Diablo

Derrola y encadenamiento de Salanás (20, 1-3)

Reinado de mil años y segundo combate escatológico (20, 4-10): derrota definitiva del Diablo y aliados

El juicio final $(20,11-15)$

El mundo nuevo, la nueva Jerusalén $(21,1-22,5)$

El ciclo y la tierra nuevos / la Jerusalén celestial $(21,1-8)$

La novia, la esposa del Cordcro / la Jerusalén celestial (21, 9-27)

El paraíso $(22,1-5)$ 
Conclusión y saludo epistolar $(23,6-20.21)$

Después de la estructura, veamos, en síntesis el contenido de los cinco septenarios:

\section{El primer septenario}

Si todo el Apocalipsis ha recibido una última configuración en forma de carta (véase $1,4-8$ y 22,21 ) no tiene por qué sorprendemos que el primer septenario esté formado por siete cartas dirigidas a siete iglesias que, por el número, simbolizan a la Iglesia universal. Con ello Juan entronca con un género literario muy común en el cristianismo primitivo (piénsese en las carlas de Pablo, de Juan, etc.). Como nota Charlier ${ }^{7}$, una carta, por definición, es un escrito. Y si se trata de una revelación es una Escritura, es decir, una palabra fija, que puede servir de polo de relerencia en todo momento para ver si una comunidad vive o no de acuerdo con el evangelio. Esto es algo fundamental en los momenlos de crisis, y más si ésta está provocada por una persecución que ha causado ya muchos mártires. Por ello Juan intenta, ante todo, con sus cartas - y con lodo el septenario inicial- reconfortar y animar a sus comunidades. Para ello empieza mostrándoles, en una visión inicial (Ap 1, 9-20), que el Hijo del hombre (idéntico con el Cordero degollado y, por tanto, con Jesús de Nazaret) es, por don de Dios, el auténtico Señor de la historia y el encargado del juicio sobre el mundo (un tema muy familiar en las tradiciones apocalípticas y en las comunidades joanneas), preparando así el juicio definitivo sobre la historia que Jesús, el "Rey de reyes y Sefior de señores" (Ap 19, 16) realizará en el quinto septenario (con el cual este septenario forma inclusión).

Además, y entrando en el texto de las cartas, Juan va indicando a las comunidades cuáles son sus cualidades $\mathrm{y}$, a la vez, y con un tacto notable, cuáles son sus defectos. Pues con su escrito intenta movilizar a las comunidades cristianas para que, recordando su amor primero (véase Ap 2,4), den testimonio prolético en medio del mundo que las persigue y corrijan los defectos y herejías que se están introduciendo en ellas (un motivo que encontramos en los escritos cristianos tardíos del Nuevo Testamento: véase Hb 10, 19ss; IP 1, 13ss; 4, 12ss, etc.). En este sentido son muy significalivas las últimas palabras de Jesús en la última carta (¡no es casual que estén precisamente en este lugar!), pues nos dan el sentido profundo del septenario, a la vez que son clave de lectura que anticipa el contenido de toda la obra: una obra que quiere anunciar tanto la promesa de Dios que llegará a ser, al linal, el Dios-con-nosotros (véase Ap 21, 3), como exhortar también a la conversión, pues el que no se convierta de sus pecados y connivencias con el mal, será objeto de la ira de Dios, como muestran a cabalidad el cuarto y quinto septenario (véase también los septenarios segundo y quinto). Efectivamente, en Apocalipsis 3, 19-21 leemos: "Yo a los que amo, reprendo y corrijo. Sé, pues, ferviente y arrepiénteıte. Mira que estoy a la puerta

Universidad Centroamericana José Simeón Cañas 
y llamo; si alguno oye mi voz y me abre la puerta, entraré en su casa y cenaré con él y él conmigo. Al vencedor, le concederé sentarse conmigo en mi trono, como yo también vencí y me senté con mi Padre en su trono". No tiene que sorprendemos, entonces, que todo el septenario concluya con una liturgia celestial (véase Ap 4) en la cual la creación, simbolizada por los cuatro animales, y cl pueblo de Dios del Antiguo y Nuevo Testamento, simbolizado por los veinticuatro ancianos, cantan la gloria y el poder de Dios, un poder que triunfará plenamente y se manifestará definitivamente como tal en la última visión del quinto septenario.

Con este septenario, el autor ha puesto claramente de manificsto al lector cuáles son las dos pistas fundamentales de lectura que le propone, literaria una y teológica la oura.

La pista literaria aparece en el modo regular, paralelo y sistematizado - podríamos incluso dccir "estereotipado"- con que Juan formula todas las cartas. Pero, a la vez, el conjunto de las cartas revela también una cstructura concéntrica, muy bien pensada, y un progreso en el pensamiento. Por otro lado, aunque las cartas tienen un tono como hicrálico, no son simples repclicioncs - cada carla comienza con uno de los tílulos que ha recibido $\mathrm{cl}$ Hijo del hombre $\mathrm{cn}$ la visión inicial-, sino que hay un auténtico progreso dentro de cllas ${ }^{73}$.

\section{Estructura concéntrica de las siete cartas}

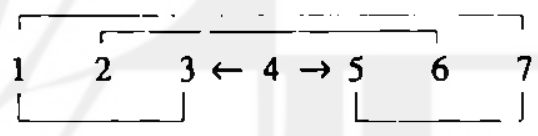

La pista teológica nos la da cl contenido del primer septenario. Más que especular sobre el lin del mundo, cl autor quiere hablar, de modo bien concreto, del aqui y ahora de sus iglesias, a fin de ayudarles a discemir los signos de los tiempos y exhortarlas a optar, en su vida cotidiana, por el Cordero degollado y por los valores que El vivió y ahora ešán concretados en su evangelio.

Una vez ha indicado, en este septenario, la perspectiva fundamental con la cual quiere él que el lector aborde su obra, Juan puede ampliar ahora el horizonte en los ures septenarios centrales del Apocalipsis. Para ello sitúa la vida de sus comunidades en el marco de la historia universal y les descubre las fuerzas que configuran, en lo más hondo, dicha historia.

\section{El segundo seplenario}

Este septcnario forma una unidad íntima con el tcrcero y cl cuarto, confirmando la estruclưa concéñutrica de la obra. De alpún modo anticipa la estructura 
(la pone al descubierto, revelándola) de los dos sepıcnarios que sigucn, quienes, a su vez, tienen una estructura claramente paralela. Es como si el autor quisiera anticipar aquí la visión celeste de las fuerzas que configuran la historia, revelando su significado profundo. Por eso, el septenario habla de un libro sellado con siete sellos (véase Ap 5, 1). El libro contiene el plan de Dios sobre la historia ${ }^{74}$. Pero dicho plan permanece secreto, en el fondo, para los seres humanos que sólo conocen de la historia lo más superficial's. Si esto es verdad, incluso con respecto a la historia más reciente y a acontecimientos aparentemente muy conocidos (¿qué sabemos, en verdad, sobre el trasfondo de los asesinatos de $\mathrm{Ke}$ nnedy, de Mons. Romero o de los jesuitas de la UCA? ¿qué sabemos de la guerta de Irak?), mucho más lo será con respecto a ouros acontecimientos. Por eso, Juan subraya que dicho libro está sellado con siete scllos, es decir, totalmente. La pregunta que se plantea, entonces, es averiguar quién es capaz de solear esios sellos (véase Ap 5, 2), es decir, de revelar el sentido más profundo de la historia. Para Juan la respuesta es clara. Sólo Cristo (véase Ap 5, 3ss) pone en marcha, definitivamente, el plan de Dios en la historia y es capaz, a la vez, de revelar su significado más profundo (véase Ap 5, 9-10).

Pero, junto con el papel fundamental de Cristo, el autor quiere revelar también ouros cuatro aspectos de la historia, que luego desarrollará, ampliándolos sucesivamente, en los dos septenarios que siguen. Por un lado quiere revelar que la acción liberadora de Dios encuentra en la historia unas fuerzas negativas que intentan contrarrestar dicha acción. Estas fuerzas son expliciadas, en el quinto sello (véase Ap 6, 9-11), con el motivo de la persecución que está sufriendo la comunidad. Pero, por otro lado, quierc revelar lambién que dicha persecución no es la última palabra de Dios sobre la historia. Pues a la comunidad se le da la buena noticia de que Cristo, que es el auténtico Señor de la historia (por don de Dios, su Padre), ha salido ya para vencer (véase Ap 6, 1-2) y que, por tanto, cl bien acabará triunfando sobre el mal (Dios hará justicia a los mártires, una justicia que éstos exigen en Ap 6,11-12). Y esta victoria del bien no será sólo parcial y temporal, sino definitiva, pues como indica el sexto sello (véase Ap 6, 12-17) estamos ya a las puertas del nacimiento del mundo nuevo, como lo muestran los signos apocalípticos que se manifiestan ya en nuestra historia. Mientras tanto, y éste es el tercer aspecto que el autor quiere destacar aquí, los males que dominan este mundo no son castigos ciegos o absurdos (de Dios), sino que son, como lo indican los cuatro primeros sellos (sobre todo el segundo, el tercero y el cuarto que anticipan las plagas que se explicarán luego, en clara alusión a las plagas de Egipto, en los dos septenarios que siguen), llamadas a la conversión de los incrédulos (como en Ex 7, 13. 22; 8, 15; 9, 35; véase también 9, 12; 10 , $1.20 ;$ y 7,$14 ; 9,34)$. Pero, como ocurrí ya con el faraón en Egipto, Juan prevé que la lógica del imperio y de sus aliados, llevará a los malvados a no convertirse. Por último, Juan quiere subrayar también que a la comunidad lc toca, entonces, mantenerse fiel a los valores del Cordero degollado, aun a costa de la Uigitalizado por Biblioteca "P. Florentino Podoate, S. 
propia vida (del martirio), confiando en la salvación final de Dios (que los mártires viven ya anticipadamente: véase Ap 7, 9-17), cuando Dios les haga participar del tuiunfo del Cordero de pie (resucilado) ante el trono de Dios. A ellos se les promete que "ya no tendrán hambre ni sed; ya no les molestará el sol ni bochorno alguno. Porque el Cordero que está en medio del trono los apacentará y los guiará a los manantiales de las aguas de la vida. Y Dios enjugará toda lágrima de sus ojos" (Ap 7, 16-17).

Como todo esto tiene su incidencia en el mundo, con este septenario el autor prepara al creyente para que descubra que cl conflicto entre los valores evangélicos y los intereses del "mundo" (entendiendo aquí "mundo" en el senuido negativo que suele tener en el cuarto evangelio ${ }^{76}$ ) es un conllicto permanente que exige, por tanto, no sólo la vigilancia, sino también una opción permanentc. Con esta exhortación al discemimiento, Juan deja resonar un motivo que es fundamental también en el Cuarto Evangelio, con el que nuestra obra está emparentada claramente $^{\pi}$.

Con este septenario, el autor ya ha anticipado lo fundamental de su revelación. Pero aún no ha desvelado, en toda su profundidad, lo que está ocurriendo en el mundo. Por eso, para que el lector descubra la dinámica del rclato y de la revelación, desplaza, excepcionalmente, la apertura del séptimo sello, cuyo contenido no es aún revelado (los séptimos momentos de los septenarios centrales se refieren al futuro inmediato que espera la comunidad, es decir, a la caida del imperio romano, anticipación de la derrota definitiva del mal que se nos narrará en el quinto septenario), hasta después de la liturgia linal del segundo septenario. De este modo aparece claro que cl contenido de dicho sello no puede ser desvelado aún (por eso no se da su contenido), sino que para ello hay que leer, primero, el contenido del tercer septenario que es como una ulterior explicitación (en cuanto al contenido, no temporal: ¡no se trata de acontecimientos sucesivos en el tiempo!) del septenario que acabamos de leer.

\section{EI tercer septenario}

Es el septenario central del Apocalipsis. De ahí que sea el más desarrollado, pues constituye el corazón de la revelación que Juan quiere comunicar a sus comunidades. No es casual que el autor haya escogido como símbolo las trompetas. Pues con este septenario el autor quiere llamar a la movilización (véase Jr $4,5 ; 1 C 14,8)$ de los cristianos en el momento actual, decisivo, de la historia. Las siete trompetas anuncian, por un lado, las desgracias que aguardan al mundo si se cierra (¡como cree Juan que lo hará!) a la llamada de Dios a la conversión. En este sentido, el simbolismo de las plagas que encontramos en las seis primeras trompetas quiere indicar, como hemos visto antes a propósito del segundo septenario, que los males del mundo no son fruto de la arbitrariedad o malevolencia de un Dios terrible, sino un llamado a la conversión (por esto en este Digitalizado por Biblioteca "P. Florentino Idoate, S.J."

Universidad Centroamericana José Simeón Cañas 
septenario se acrecicntan las consecuencias negativas de las plagas con respecto al segundo scptcnario, pero sin llegar a la totalidad que alcanzarán en el cuarto septenario, que representa el último llamado de Dios a la conversión). Por otro lado, el autor manticne aquí la estructura que ya puso de manifiesto en el septenario anterior: las cuatro primeras trompetas se refieren a las plagas que afectarán a la naturaleza, micnıras que la quinta y la sexta atormentarán a los hombres; la séptima, como era de csperar en este septenario que prepara el cuarto septenario y está construido paralclamentc a ćl, no es descrita sino sólo anunciada (véasc Ap 11, 15a).

A la luz. de las alusiones al Antiguo Testamento podemos descubrir algo que es muy importante para la comprensión adecuada de cste septenario: que su aumósfera es de claro tono pascual (nos recuerda la actuación fundamental del Dios liberador en el Antiguo Testamento). Con cllo nos ayuda a descubrir el significado fundamental que tiene para la historia del mundo y de la comunidad la actuación definitiva y libcradora de Dios en el Nuevo Testamento. Me refiero a la resurrección (las comunidades joanneas prefieren hablar de exaltación: véase Jn 3,$14 ; 8,28 ; 12,32$ s) dc Jesús. Por eso, antes de que suene la sćptima trompeta, cl autor intertumpe el relato para desartollar un amplio intermedio (el primero de este septenario; cl segundo lo pondrá una vez la séplima trompeta haya sonado, con lo cual ahora los dos intermedios la enmarcan). Con ello, a la vez que retarda el sonido de la séptima trompeta (dando lugar así a la conversión y explicando quizás también de paso el retraso de la parusía" ${ }^{78}$ ), permite indicar claramente al creyente cuál es su vocación cristiana en este momento, si tiene bien presente el significado fundamental de la resurrección de Jesús.

Efectivamente, así conviene que interpretemos Apocalipsis 10, 1-11.14 (si se indica aquí en Ap 11, 14 que es ahora cuando el "segundo ay" ha pasado, y no cuando acabó de contarse lo que comportaba la sexta trompeta, es que lo que se dice en estos capítulos no se refiere tano al futuro, que es descrito en los séptimos momentos de los septenarios, cuanto al presente que vive la comunidad). Pues en Apocalipsis 10, con la aparición del ángel majestuoso que lleva en su mano el librito que Juan es invitado a comer (con una clara alusión a la vocación profélica de Ezequiel: véase Ez 3, 3.14), Juan quiere hacer referencia a la vocación profética del vidente. Por eso se le indica que, una vez haya comido el librito, éste le resultará dulce y amargo a la vez: dulce, porque su predicación contendrá una Buena Noticia elerna (véase Ap 14,6), el triunfo de Dios, que en este septenario queda condensado en el anuncio pascual del triunfo de Jesús sobre Satanás que es narrado, simbólicamente, en el segundo intermedio de este septenario; pero amargo también, pues ha de anunciar el castigo a los que se cierren al mensaje de Dios y dicho anuncio le comportará al profeta la persecución y, quizás, el martirio"s.

La descripción de la vocación profética de Juan ha preparado el capítulo 11. Digitalizado por Biblioteca "P. Florentino Idoate, S.J."

Universidad Centroamericana José Simeón Cañas 
en el cual se simboliza la situación que csá viviendo ahora la comunidad, destacando dos aspectos complementarios que acompañan siempre la vida de las Iglesias. En primer lugar, Juan quicre destacar que, a pesar de que las apariencias puedan hacer pensar lo contrario, las iglesias están protegidas por Dios. Esto es lo que se quicre indicar, simbólicamente, con el hecho de que cl vidente recibe la siguiente orden que cstá inspirada en Ezequiel 40, 1-5 y Za 2, 5-9: "Levántate y mide el Santuario de Dios y el altar, y a los que adoran en él" (Ap $11,1)$. Pcro, en segundo lugar, ello no excluye que las iglesias sean perseguidas y martirizadas por cl imperio en cl tiempo limitado - los tres años y medioque caracteriza su vida. Esto es lo que se quiere significar con la orden de que no mida cl patio extcrior del santuario, "porque ha sido entregado a los gentiles, que pisotcarán la Ciudad Santa cuarenta y dos meses" (Ap 1 1, 2) ${ }^{\text {no }}$.

Partiendo de esta realidad, en Apocalipsis 11, 3-13 se desarrolla, cntonces, la vocación profética que han recibido todos los cristianos (en la línca de lo que decía Pedro a propósito de Pentecostés en Hch 2, 14-21). Ya Marcos había indicado antes, en un texto también apocalíptico, que antes del final escatológico de la historia el evangelio debía ser predicado a todas las naciones (véase Mc 13, 10), dando con ello una tarea a su Iglesia, aunque cllo le compone persecuciones (véase Mc 13, 9-13). Una tarea que es válida incluso después de la caída de Jerusalén, a la que se alude en Marcos 13, 14ss. En el mismo sentido, Juan quicre subrayar a su comunidad que debe dar testimonio prolético cn cl mundo antes de que suene la séptima trompeta ${ }^{81}$. En efecto, los dos testigos (dos era condición para un testimonio válido: véase Jn 8,17 y Dt 19, 15), de los cuales se indica por ures veces que son "profetas" (véase Ap 11, 3.6.10), hacen referencia a la función profética que deben desempeñar ahora los cristianos que quieran ser fieles al Cordero degollado. No es obstáculo para esta interpretación el que sean descritos con unos rasgos que aluden claramente a los dos grandes profelas del Antiguo Testamento, Elías y Moisés, al afirmar de cllos, por un lado, que "lienen poder de cerrar el cielo para que no caiga la lluvia" (véasc 2Rc $1,17)$ y, por otro, que lienen poder también para desencadenar las plagas (véasc Ex 7,$17 ; 11,10$ ) sobre el mundo que no se convierte y les persigue (véase Ap $11,6)$. De ellos se esperaba su retomo para los tiempos mesiánicos (véase Dt 18, 18; Ml 3, 23). Pues, si se leen estos texlos en el contexto en los cuales los ha colocado Juan, se ve que lo que quiere indicar el autor con ello es que el testimonio profético cristiano es el cumplimiento de lo anunciado en el Antiguo Testamento, una idea muy familiar en el Apocalipsis ${ }^{82}$. A la vez se les anuncia (como ya lo había hecho Jesús con sus discípulos: véase Jn 16, 1-4) que compartirán el destino de Jesús, es decir, su muerte y resurrección, pues provocarán la oposición al mundo (véase Ap 13, 7-10), que llegará, inciuso, a asesinarlos y se alegrará con su muerte (como se alegraron muchos del martirio del Monsefior Romero o de los jesuitas de la UCA). Pero se les anuncia también que Dios no los dejará de su mano, incluso en esta vida (véase Ap 11, 5), y que, pasado un Digitalizado por Biblioteca "P. Florentino Idoate, S.J."

Universidad Centroamericana José Simeón Cañas 
tiempo breve, aparecerán, incluso a sus enemigos, como compartiendo la glorificación de Jesús (véase Ap 11, 11-13). Juan quiere afirmar también que con su testimonio los profetas cristianos acelerarán la venida del reino de Dios. Por eso es tan importante para él que los cristianos cumplan con su misión de profclas ${ }^{83}$. Por otro lado, la noticia de que algunos se convertirán (véase Ap 11,13) es un mensaje de consolación para los que viven en medio del "segundo ay", es decir, en medio de las pruebas escatológicas, que está viviendo la comunidad, (véase Ap 9, 13-11, 14) que preparan el toque de la séptima trompeta. Esla anuncia el castigo definitivo de Dios contra el imperio romano y el acercamiento de los últimos tiempos. Con ello se confirma lo que hemos propuesto antes como tesis: que la sexta trompeta (véase Ap 9, 13-21) y la reflexión que retarda cl toque de la séptima tompela (Ap 10,1-11, 14 está situado antes de Ap 11, 15a) se refieren al tiempo de la Iglesia que está viviendo el autor ${ }^{\text {B4 }}$.

Pcro cuando suena la séptima trompela en Apocalipsis $11,15 a$, el autor, como había ocurrido ya en el segundo septenario, no describe los resultados de dicho toque (es una manera de invitamos a que leamos el siguiente septenario, el cuarto, como explicación definitiva de lo que se ha anunciado de antemano en este septenario), sino que deja resonar un cántico en el cielo (véase Ap 11, 15b19), que anticipa el uriunfo final de Dios, que va a hacer justicia restableciendo su reinado, también aquí en la tierra. No es casual que, precisamente en este lugar, Juan recuerde el motivo que subyace a toda la reflexión leológica del Apocalipsis: la fidclidad de Dios a la alianza que estableció con su pueblo (véase Ap 11, 19: aparece en el Santuario el Arca de la Alianza).

De todos modos, y confirmando su predilección por las estructuras concénuricas, el autor, antes de dejar resonar la liturgia final celestial con que suele concluir sus septenarios, se toma aquí otra vez un receso para incluir un segundo interludio largo que, formando inclusión con el primer intermedio que hernos encontrado en Apocalipsis 10,1-11, 14, ponga al descubierto las fuerzas últimas que configuran la hisloria y cómo éstas, incluso después de la resurrección de Jesús, siguen incidiendo hoy en el mundo (véase Ap 12-13).

Para ello, Juan desvela, en primer lugar, en Apocalipsis 12, el trasiondo de la lucha a muerte que enfrenta a los cristianos con el imperio. Que se está refiriendo al trasfondo último nos lo indica ya simbólicamente al comienzo cuando destaca que las "grandes señales" aparecen "en el cielo" (véase Ap 12, 1. 3). Aunque, luego, cuando aparezca por tercera y última vez una "gran señal" (en Ap 15, 1), nos hará caer en la cuenta de las consecuencias terrenas de este trasfondo celestial, obligándonos, una vez más, a no quedarnos sólo mirando al cielo, sino a mirar también a la tierra que es donde el cristiano está llamado a dar su testimonio profético. Con ello, de paso, muestra también, literariamente, la relación entre este septenario y el siguiente.

Lo primero que nos presenta aquf Juan es "una mujer", vespida de sol, con la Universidad Centroamericana José Simeón Cañas 
luna bajo sus pies, y una corona de doce estrellas" (Ap 12,1). Hoy los especialistas coinciden en afirmar que dicha mujer simboliza el pueblo de Dios (las doce estrellas representan las doce tribus de Isracl que va a ser reconstiuido con la venida y triunfo del Mesías"s), que está a punto de dar a luz (véase Ap 12,2). Frente a ella, Juan sitúa a la serpicnte roja, que por su color, las cabezas ( isie(e!), los cuemos (¿diez!) y las diademas con que está adomada representa el poder demoníaco (en Ap 12,9 se la identifica, incluso, claramente: "la serpiente antigua, cl llamado Diablo o Satanás, el seductor del mundo entero"), que quiere acabar con la mujer y su descendencia, como lo intentó ya al comienzo de la creación (véase Gn 2-3).

Pero cuando "la mujer dio a luz. un Hijo varón, el que ha de regir a todas las naciones con cetro de hicro" (por la descripción se ve claro que se trata del Mcsías) "su Hijo fuc arrcbalado hasta Dios y hasta su trono" (Ap 12,5), con lo cual el Diablo, que ha intentado devorarlo (véase Ap 12,4b), no sólo no consigue acabar con él, sino que va a sufrir las consccucncias, en bucna ironía joannea, de esta elcvación del Hijo a Dios. Con ello se ve claro que el autor, más que referirse al nacimiento del Mesias, quicre referirse, primariamente, con unas imágenes que nos resultan familiares por el Cuarto Evangelio, a la exaltación del $\mathrm{Hijo}^{\mathrm{Bb}}$. Lo que cl autor nos quiere ensctíar con estas imágenes es que sólo a la luz de la pascua se comprende, en toda su profundidad, el significado de la encarnación. Como indica muy bien Charpentier" "la mujer simboliza al pueblo de Dios, a la Iglesia, que da nacimiento al Mesías en el drama del calvario. Satanás, dertolado, se arroja contra los demás hijos de la mujer, contra todos los cristianos, y les hará la guerra durante todo el tiempo de la historia". Como ocurría ya en el Cuarto Evangelio, la cruz. es vista como exaltación (véase Jn 3, $14 ; 8,28 ; 12,32 s$ ) y como trono en cl cual Jesús rcina (véase Ap 12,5$)^{88}$. En este sentido, cruz y exaltación no son dos momentos distintos, en la escucla joannea, sino dos caras de una misma realidad.

El (ragmento siguiente (véase Ap 12,7-12) saca, entonces, las consecuencias de esta victoria pascual y nos presenta la dimensión última de esta derrota del demonio con la imagen clásica (mítica) de la lucha entre Miguel, que está colocado al frente de sus ángeles, y la serpiente, que también está al frente de sus ángeles (los ángeles caídos). Lo que el autor quiere decimos con estas imágenes es que con la exaltación de Jesús ha empezado ya el reinado del Cordero degollado. Ello implica que Satanás ha sido vencido y ha perdido su poder más radical (todo ello está simbolizado con el hecho de que es expulsado del cielo, una imagen que encontramos también, por otro lado, en $L c 9,18$ y Jn 12, 31-32). Pero este hecho no significa que Satanás carezca ya de todo poder. Pues no hemos llegado aún a la plenitud del reino. Por eso Juan, para prevenir al lector de las amenazas que para el cristiano comportan aún los "poderes del mal", muy activos en la tierra, antade una advertencia seria en Apocalipsis 12,12b: "¡Ay de la tierra y del mar! porque el Diablo ha bajado donde ustedes con gran furor, 
sabiendo que le queda poco tiempo". Pero incluso aquí no quiere el autor que deje de resonar también una nota positiva. Pues le indica a la comunidad que, incluso en medio de esta lucha encarnizada que está viviendo, el pueblo cristiano sigue siendo protegido por Dios, como lo fue en otro tiempo el pueblo de Israel en el desierto (véase Ap 12, 13.16 con Ex 19, 4 y 14, 27ss). Pero ello, claro está, no quita que ahora el demonio persiga encarnizadamente "a los que guardan los mandamienlos de Dios y mantienen el testimonio de Jesús" (Ap 12, 17), dos aspectos que, según el autor del Apocalipsis, deben caracterizar aquellas actitudes cristianas que él quicre fomentar y consolidar en su comunidad como signos de identidad cristiana.

Con ello Juan nos ha descifrado lo [undamental sobre las realidades más hondas que conliguran nuestra historia. Pero quiere clarificar aún más lo que acaba de decir, ayudando a su comunidad a desenmascarar las fuerzas demoníacas que, basándose en la mentira, quieren engañar a los cristianos. Por eso en una segunda parte de este intermedio largo (y preparado por Ap 12, 18), quiere desenmascarar a las potencias aliadas de Satanás aquí en la tierra y explicar de qué recursos se valen para oprimir a la Iglesia. Están representadas por dos bestias. Por un lado, la bestia del mar (véase Ap 13, 1-10), que simboliza la Roma poderosa políticamente. Es como la encamación de todos los imperios totalitarios, como puede ver claramente cl lector iniciado en el Antiguo Testamento por el hecho de que en Apocalipsis 13,2 se le aplica la descripción de los imperios enemigos del pueblo de Israel que aparecen en Danicl 7, 4-6. Se trata del imperio que, en su orgullo, se idoliza a sí mismo y martiriza a los cristianos que no quieren adorarlo (véase Ap 13, 4-7) ${ }^{\text {s9. }}$.

Y, por otro lado, nos presenta también a la bestia de la tierra (véase Ap 13. 11-17) que, más adelante (véase Ap 19, 20 y 20,10), es denominada "el falso profela". Es el simbolo de la propaganda religiosa (y de las ideologías) que están al servicio del imperio (véase Ap 13, 12-15). Dichas "sectas" son muy peligrosas pues utilizan su influjo no sólo para engañar a los ingenuos, sino también para marginar, incluso económicamente (ya se ve cuál es el ídolo más peligroso), a lodo el que no quiere adorar a la primera bestia (véase Ap 13, 1617) $)^{90}$.

En este sentido, el dragón y sus dos acólitos (son creatura e imagen del dragón, formando así una especie de trinidad satánica) expresan el peligro que comporta para los cristianos un Estado (es decir, todo Estado) totalitario y despótico, como el de Roma en ticmpo del emperador Domiciano (al que se alude en Ap 13, 18 como hemos visto), que quiere convertirse en ídolo y obligar a los cristianos a renunciar a sus valores para aceptar, en su lugar, los del imperio. Juan insiste aquí en estos aspectos porque cree que es absolutamente necesario que el Icctor se mantenga vigilante antc estas amenazas del poder civil que se vale, incluso, de la propaganda (pseudo) religiosa para engañar a los hombres y Digitalizado por Biblioteca "P. Florentino Idoate, S.J."

Universidad Centroamericana José Simeón Cañas 
así garantizar la perduración de su poder iniquo e injusto. Se trata, pues, de un mensaje muy actual si uno piensa en la manera como el actual imperio del norte utiliza en Centroamérica las sectas o la teología neoliberal (conservadora) para contrarrestar aquellas teologías que, como la teología de la liberación, están en sintonía con la teología del Apocalipsis (y de los evangelios sinópticos, por no hablar ya del Antiguo Testamento).

Y como la dureza de la persecución en la comunidad es nolable y, por otro lado, parece que el poder del imperio es inconmovible (de hecho lardó algo más de tres siglos en caer), por eso Juan no quiere terminar este septenario sin que resuene en la liturgia celestial), al final de este septenario (véase Ap 14, 1-5), el cántico triunfal de "los que siguen al Cordero a dondequiera que vaya, y han sido rescatados de entre los hombres como primicias para Dios y para el Cordero" (Ap 14, 4).

Con todo ello, el autor nos ha preparado para la lectura del cuarto septenario en el cual nos mostrará, ahora ya de un modo definitivo, lo que le aguarda al imperio cruel que no quiere convertirse y martiriza a los cristianos.

\section{El cuarto septenario}

Con este septenario concluye el núcleo central del Apocalipsis. Explicita, de modo claro y definitivo, lo que el segundo septenario había apuntado y el tercero había preparado (por eso este septenario está construido de modo que haya un paralelismo estricto, en cuanto a las plagas, con el septenario anterior, pero de modo que aparezca que el castigo no sólo aumenta, sino que ahora ya se anuncia el castigo definitivo de la bestia del mar, es decir, del imperio, cuya caída será narrada y cantada, subrayando que ello se debe a que no ha querido convertir$\mathrm{se}^{\mathrm{pl}}$ ).

No debe sorprendernos, entonces, que el autor escoja como simbolo las copas $^{92}$ que, en cuanto "copas de la cólera de Dios" (véase Is 51, 17. 22; Jr 25, 15), significan los castigos y la ruina definitiva que aguarda a los imperios totalitarios que, como el de Roma, no aceptan el señorío de Dios y quieren, a su vez, convertirse en dioses, sin escuchar las llamadas a la conversión que Dios les manda a través de las plagas.

Como éste es el último de los ures septenarios centrales, ahora sí que Juan narrará el contenido de la séptima copa (véase Ap 16, 17-21) que consiste en la cafda de Roma. Aquí Juan se preocupa por identificar claramente el Imperio contra el cual van dirigidas, prioritariamente, sus amenazas. Pues, después de denominarla "la célebre Ramera, que se sienta sobre grandes aguas: con ella formicaron los reyes de la tierra, y los habitantes de la tierra se embriagaron con el vino de su prostitución" (Ap 17, 1b-2), nos dice en Apocalipsis 17, 9 que se trata de "la ciudad de las siete colinas". Se trata de la ciudad que se embriaga Digitalizado por Biblioteca "P. Florentino Idoate, S.J." 
con la sangre de los santos y de los mártires de Jesús (véase Ap 17, 6). Por eso concluye Juan con un canto poético sobre la caída de Babilonia (Roma) que, por un lado, expresa una alegría inmensa por la caída del imperio opresor. Pero, por otro, reflcja tambićn la admiración que siente Juan por dicha ciudad y por su esplendor. Por ello lamenta también su perdición por haber rechazado a Dios y haberse condenado así a la destrucción' ${ }^{93}$. Domina, pues, este septenario la atmós[era del juicio de Dios. El autor sabc, por experiencia sapiencial y evangélica, que la encarnación de Dios en las realidades humanas no lleva, de hecho, al mundo a la conversión. Así ocurrió ya en tiempo de Jesús ${ }^{\text {th }}$. Pues su Bucna Noticia, que Matco condensa en textos como el sermón de la montaña o cn el examen final del scrmón cscatológico (véasc Mt 25, 31-46) y Lucas en el cambio de estructuras anunciado por María en cl Magnificat (véase Lc 1, 51-53), "tiene" que provocar el rechazo de un mundo que ama más las tinicblas que la luz, porque sus obras son malas (véase Jn 3, 19). Un Dios que, contra toda "lógica humana", que es una "lógica de la equivalencia" (es decir, una lógica que se guía sólo por las reglas del mercado libre, en cl cual los poderosos - por ejemplo, el norte- pueden imponer lo que consideran "equivalente" a lo que reciben a cambio, imponiendo unas leyes que deficnden sus intereses) propone una "lógica de la gratuidad" que fundamente la "lógica de la fraternidad universal" "es, no puede contar con la aprobación de cste mundo y de los poderes que lo configuran. Un mundo estructurado asi acaba por matar al proleta Jesús que denuncia su injusticia, como procura asesinar también a todos los que, con valentía profética, es decir, cristiana, siguen radicalmente a Jesús en su denuncia de la injusticia.

Pero como el juicio, para el cristiano, no es nunca la palabra definitiva de Dios sobre la historia, todo el septenario vicne enmarcado por un tono positivo que proyecta su luz, incluso cuando se va a hablar del castigo definitivo. Me refiero al comienzo de la visión inaugural del scplenario y a la liturgia celestial con que concluye. La primera parte de la visión preparatoria (véase Ap 14, 613) empicza anunciando una "Buena Noticia elerna" (Ap 14,6) a todos los pueblos de la lierra, que no sólo incluye cl juicio sobre Babilonia (véase Ap 14, 7-11), sino tambićn la promesa de que terminarán los sufrimientos de los santos que han guardado los mandamientos de Dios y la fe de Jesús (véase Ap 14, 12). Por eso este primer fragmento introductorio concluye con una bienaventuranza que Juan pone en boca del Espírilu: "dichosos los muertos que mueren en el Señor. Desde ahora, sí, que descansen de sus faligas, porque sus obras les acompañan" (Ap 14, 13). Se trata de un texto posițvo que, enlazando con el cántico de Moisés y el cántico del Cordero (véase, luego, Ap 15,3-4) —el cántico recuerda las grandes acciones del Dios liberador en favor del pucblo de Dios (la salida de Egipto y la resurtección de Jesús)-, forma inclusión con la liturgia celcstial que cncontramos al final en Apocalipsis 19, 1-8. En ćl canta cl triunfo de Dios y cl regocijo de la lglesia porquc "han Ilegado las bodas del Cordcro" Digitalizado por Biblioteca "P. Florentino ldoate, S.J."

Universidad Centroamericana José Simeón Cañas 
(Ap 19,7). Con ello, Juan ya nos ha preparado para cl último septenario que concluirá con este motivo (véase Ap 21, 3-4), invitándonos, asi, a seguir leyendo su obra, pues piensa que la historia no habrá llegado, probablemente, a su término con la caída de Roma. Por otro lado, también la segunda pare de la introducción al septenario (véase 14, 14-20), que prepara el discemimiento entre buenos y malos, simbolizados, respectivamente, por las imágenes de la cosecha y de la vendimia*s (el contenido de la vendimia viene significado, precisarnente, por las siete copas del septenario: véase Ap 16), contiene, a su vez, una buena noticia para la Iglesia: que el Juicio será realizado por el Hijo del hombre (véase Ap 14,14 ) que sostiene un su mano derecha a todas las iglesias (véase Ap 1, 17-20).

\section{El quinto septenario}

Con este septenario concluye la obra. Tanto por su estructura (siete visiones), como por su contenido, se ve que, por un lado, forma inclusión con el primer septenario y que, por otro, lleva a su plenitud la dinámica creciente que empezó a aparecer en el segundo septenario y que culminó en cl cuarto ${ }^{97}$. Por la inclusión con el primer septenario, Juan subraya que toda la obra está hablando. ante todo, del presente de la Iglesia y que quiere ayudar al lector a discernir cómo debe actuar el cristiano que lorma parte de la Iglesia militante si quicrc llegar hasta la Iglesia triunfante. Por ello, si la visión inicial del primer septenario (véase Ap 1, 9-20) presentaba a un Cristo triunfante, que tiene en su mano derecha a las iglesias que se encuentran inmersas en medio de una persecución sangrienta y que están amenazadas de tibieza y desesperanza (véase Ap 2-3), ahora, en la visión final, aparece la Iglesia triunfante que ha llegado ya a su plenitud, una vez han sido vencidas, definitivamente, las fuerzas del mal, simbolizadas por el demonio y la muerte.

Por otro lado, por su relación con los septenarios centrales (la visión de Cristo, montado sobre un caballo blanco, que presenta a Jesús como juez y guerrero victorioso en Ap 19,11-16, enlaza con la apertura dcl primer sello del segundo septenario que encontramos en Ap 6, 1-2), este septenario aparecc como la culminación de la dinámica histórica que el autor nos ha ido desvclando a lo largo de su obra. Pero ahora ensancha, definitivamente, el horizonte. Pues abarca desde la aparición del Mesías, que es el inicio del reino de Dios aquí en la tierra, hasta el juicio final definitivo (véase Ap 10,11-15) y la visión del nuevo mundo, la Jerusalén celestial, el paraíso recreado (véase Ap 21, 1-22, 5), que aparecerá cuando se consumen las bodas del Cordero con el pueblo de Dios y Dios sea el Dios-con-ellos (véase Ap 21, 3). No es casual, entonces, que en la visión central de este septenario (véase Ap 20, 1-3) se haga alusión a la exalıación de Jesús, que comporta la derrota lundamental de Salanás —el encadenamiento durante mil antos to simboliza

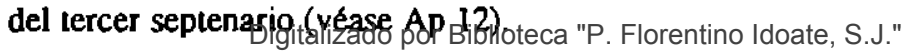

Universidad Centroamericana José Simeón Cañas 
Aparte del papel fundamental de Cristo, que domina todo el Apocalipsis, dos son los molivos fundamentales que configuran este septenario. Por un lado, el encadenamiento de Satanás durante un tiempo muy largo (simbolizado con los mil afjos) que, como hemos visto, se refiere al tiempo actual de la Iglesia que se inició con la exalıción de Jesús". Si Salanás había seducido a Adán y Eva en el paraíso, ahora Satanás está encadenado, de modo que, si el cristiano cede a sus seducciones (tentaciones), será inexcusable. Estamos, por tanto, en el tiempo en el cual el evangelio puede ser vivido gracias al triunfo de Cristo, aunque ello no excluya un ataque final y definitivo al fin de los liempos (véase Ap 20,3b con Ap 20,7-10). Por otro lado, tenemos también aqui el molivo de la nueva creación, que va unido a la Jerusalén celcstial y al motivo del paraíso (véase Ap 21, $1-22,5)$. Se trata de algo que nos aguarda al fin de los tiempos, cuando se manifieste plenamentc el Señorío de Dios y Satanás y la muerte sean vencidos definitivamente. A su vez, conviene tambićn subrayar aqui, que si en la sépuima visión se nos dice que esta Ciudad Santa, la nueva Jerusalén o Iglesia triunfante, que cl vidente aguarda para el fin de los tiempos, "baja del cielo" (véase Ap 21, 2), con ello Juan quiere recordarnos que dicha Iglesia pugna ya por hacerse presente en la Iglesia terrena en la cual vivimos. En la visión inicial (véase Ap $1,16)$ se nos decía lo mismo con otra imagen, cuando se afirmaba que las iglesias cslaban en la mano derecha del Hijo del hombre. Es la Iglesia hacia la cual caminamos, en la cual Dios, por don gratuito suyo, eslablecerá su morada plenamente y en la cual todos los pucblos se encontrarán como en su casa.

Juan confiesa, pues, que esıa esperanza maravillosa un día será realidad por don de Dios. Pero sabe lambién que aún no es así, ni de lejos. Y que su realización plena escapa a las posibilidades de la Iglesia. Por eso termina su obra con una oración que le brola de lo más hondo del alma: ";Ven Señor Jesús!" (Ap 22. 20).

Notemos también, para concluir cl comentario de este septcnario, que su estructura interna confirma la estructura concéntrica que creemos que el autor ha querido dar a su obra. Vimos ya la inclusión con los grandes molivos teológicos que se prometian a las Iglesias en el séptimo septenario o que caracterizaban a Cristo. Pero a cllo hay que añadir que la estructura del septenario es también concéntrica, como ocurría ya en el primer septenario (aunque la estructura no sea idéntica en sus detalles).

Podemos esquematizarlo así (el contenido de cada una de las visiones lo hemos indicado ya, sumariamente, al proponer la estruclura global de la obra) ${ }^{100}$ :

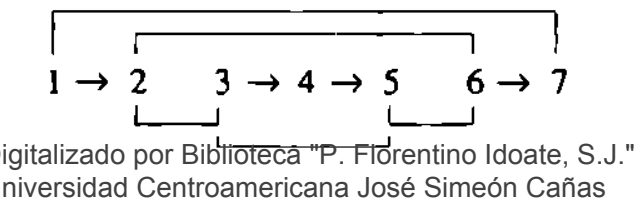


Si esto es así, como crcemos, la misma estructura confirmaría, entonces, cl significado aclual del reino mesiánico de mil años que está situado en la visión central (como el triunfo perenne de Cristo y la instauración de su reino aparecían también en el centro del Apocalipsis, es decir, en cl tcrcer septcnario). Con ello pucde verse que dicho reinado milenario no se reficre a un reinado de Cristo que tendrá lugar sólo en la ticrra en una época futura ${ }^{101}$.

Por otro lado, las visiones segunda y tercera se corresponden también, tanto temática como literariamente, formando una unidad. Pues la expresión "... todas las aves que volaban por lo alıo" (al comienzo de la segunda visión, véase Ap $19,17)$, se repite, aunque no textualmente, al final de la tercera visión: "y todas las aves se hartaron de sus carnes" (Ap 19, 21). El banquete anunciado en la segunda visión, con una clara alusión a Excquiel 39,17102, es realizado en la tercera visión. A la vez se prepara con cllo la sexta visión. Pues en Apocalipsis 19, 18, después de describirse la carne preparada para cl banquete, se concluyc, como en síntesis, con las palabras "carne de pequeños y grandes", lo cual podría formar inclusión con cl juicio final de toda la humanidad, pucs en 20, 12 Juan vuelve a cmplcar esta expresión: "Y vi a los muertos, grandes y pequeños". Con ello enmarca las cinco visiones centrales del septenario, presentándolas como un enjuiciamiento (un "discemimiento"), primero en la historia, y, luego, en la escatología, del mundo entero, "grandes y pequeños"

La primera y la séptima visión serían, entonces, como el marco de todo el septenario. Pues la primera presenta al Mesías iniciando todo el proceso del juicio y de la victoria de Cristo ( $y$ de sus iglesias), una victoria que culmina en la séptima visión con la instauración de un "orden nuevo", el nuevo Cielo y la nueva Tierra, la Jerusalén celestial, que serán como la recreación del paraíso.

\section{Conclusión}

\section{Actualidad del Apocalipsis}

Después de lo que acabamos de ver, se comprende lo que decía al comienzo de este artículo: que, desde El Salvador, el Apocalipsis recobra toda su perenne actualidad. Pues, desgraciadamente, en los dos últimos milenios no ha variado mucho lo que Juan revela sobre la historia. Cayó el imperio romano. Pero los imperios que lo siguieron no fueron mejores. Ni el germánico, ni el español (iy es bueno recordarlo, también, con motivo del "quinto centenario"!), ṇi el francés, ni el inglés, ni el chino, ni el japonés, ni el ruso, ni, en la actualidad, el norteamericano. Todos se han convertido en bestia para los pueblos empobrecidos y oprimidos de la tierra, sobre todo para sus mayorias populares. Todos han perseguido a los profetas cristianos que se han mantenido fieles al Cordero degollado y no se han dejado seducir por los pseudoprofetas que, o bien espirituali- 
zan, indcbidamente, el mensaje cristiano, quitándole su mordiente y su denuncia de la injusticia, o bicn idolizan al sistema capilalista, ¡llegando a identificar a las multinacionales con la figura del "Siervo de Yahvé"! Con ello ignoran, e incluso ocultan, las innumerables vícumas del sistema del imperio de tumo. Esto vale también, evidentemente, mutatis mutandis, para las interprelaciones light del compromiso cristiano que prcdican un ciclo que no baja a esta tierra y que, por tanto, no exige de nosotros un compromiso en favor del reinado de Dios. Pues desfiguran el rosiso de Cristo, el Cordero degollado, asesinado por no haber aceptado los valores del imperio y por haber puesto el bien de todos los seres humanos (véase Mc 3,1-6), empezando por los que tienen una vida amenazada en un mundo injusto, como criterio último y decisivo que permita conocer cuál es la voluntad concreta de Dios para sus iglesias. Con ello no encama "la Iglcsia que Jesús quería"104.

Si Juan se dirigiera hoy directamente a nuestras iglesias, volvería, creo, a hacerlo como lo hizo en el Apocalipsis. Por un lado, tendría muchos reproches para nosotros - nos exhortaria a la conversión--, pues sigue habiendo mucha tibieza en la misma Iglesia y muchos cristianos, de todo tipo, siguen doblando su rodilla ante la bestia, indiferentes al dolor $y$ al grito de los pobres y, de modo especial, al clamor de todos aquellos que han dado su vida, con generosidad, por fidelidad al Cordero degollado.

Pero vería también lo positivo. Veria los miles de mártires que, con Monseñor Romero a su cabeza ("San Romero de América", como dice bellamente Mons. Casaldáliga en una poesía), han sido asesinados por el imperio y sus lacayos, simplemente por haber sido fieles al proyecto de Jesús (a la buena noticia del evangelio) y haber sido profetas en medio de un mundo que no puede soportar las voces de los profetas. Por ello, como ocurre en el Apocalipsis, el autor nos alertaría hoy frente a unos valores engañosos que nos prometen la felicidad y quieren embotar nuestras conciencias e inteligencia, a fin de que no veamos el precio que otros pagan por nuestro bienestar y nuestro consumo desmesurados. Pero, a la vez, en un mundo amenazado de desesperanza, como ocurría en tiempo del Apocalipsis, Juan escribiría también una obra que fundamentara profundamente la esperanza cristiana. Volvería a escribir un mensaje de esperanza. Como dijo muy bien E. Bloch, "el hombre no vive sólo de pan; vive de pan y utopia". Es lo que nos recuerda el evangelio que quiere ser una "buena noticia etema" para los que "tienen hambre y sed de justicia". Creo que hoy, más que nunca, necesitamos de la utopía cristiana que en Jesús de Nazaret se hizo copía. Es lo que confiesa con toda fuerza el Apocalipsis. Y lo necesitamos para que no nos dejemos engañar por la falsa propaganda y la manipulación del imperio que domina nuestro mundo. Y para que, empapándonos de los valores que enseflo y practicó Jesús de Nazaret, pasemos por el mundo, como él, "haciendo el bien y curando toda enfermedad" (Hch 10, 38), conscientes de que, siguiendo a Jesús, hernos recibido lodos una vocación profétuca, hoy más nece-

Universidad Centroamericana José Simeón Cañas 
saria que nunca en nucstro mundo. Pues Ilcnos de su Espíritu, hemos sido enviados a anunciar a los pobres la Buena Nueva, a proclamar la liberación a los cautivos y la vista a los eiegos, para dar la libertad a los oprimidos y proclamar un año de gracia dcl Señor (véase Lc 4, 18-19). Sólo así haremos fructificar la semilla del reinado de Dios que ya cstá plantada en este mundo con la venida de Jesús y su resurrección, aunque, aparentemente, sca muy pequeña y esté mezclada con la cizaña, dentro de la misma Iglesia (véase Mt 13, 24-30. 36-43). Pues un día, por don de Dios (véase Mc 4, 26-29), dicha semilla nos admirará por su grandeza (véase Mc 4, 30-32). Hoy, por tanto, siguc sicndo verdad la promesa de Jesús con que concluye el Apocalipsis: "Sí, pronto vendré" (Ap 22, 20a). Por eso nosotros, con los empobrecidos de la ticra que creen en Jesús, nos atrevemos a decir también: “¡Amén! ¡Ven, Scf̂or Jesús!” (Ap 22, 20b).

\section{A modo de apéndice}

No quicro terminar este artículo sin recordar, con profundo agradecimicnto y cariño, a las comunidades empobrecidas y creyentes de El Salvador y a sus mártires de la fe y la jusuicia, unas comunidades que "guardan los mandamientos de Dios y el testimonio de Jesús". Ellas me han regalado los ojos para saber descubrir el misterio profundo del Apocalipsis, pues gozan de una sintonía profunda con su mensaje. Como bolón de muestra de dicha sintonía quisiera concluir con un par de textos, formulados por mis alumnos/as del profesorado en ciencias religiosas de la UCA, cuando, en 1985, les pedí que actualizaran, para sus comunidades, las cartas que aparecen en el primer septenario del Apocalipsis. Rezan asi:

Escribe el ángel de la Iglesia de San Salvador: Esto dice el que está de pie sobre el mundo, el que rige a las naciones, el Alfa y Omega, principio y fin de todo. Conozco tu conducta, tu caridad, tu fe, tu paciencia en el sufrimiento. He visto tu sufrimiento y tu lucha contra la Bestia. Pero tengo contra ti que estás perdiendo tu amor primero, que toleras a los emisarios de la bestia, estás cediendo al miedo y dejas que tus hijos sean devorados. He posado mi mirada sobre la Lierra, he visto los cadáveres en el camino, ruido de la fiesta en los altozanos, el grito del hombre en el valle; salgo al campo y uus hijos mueren a espada, el crujir de la muerte en la tierra y en el cielo. He visto cómo de entre los tuyos se postran ante los baales que ha colocado la bestia. Acuérdate, por tanto, de cómo recibiste y oíste mi palabra, no acalles la voz de mi profeta (Monsefior Romero), no adulteres la sangre de tus mártires, guárdala y arrepiéntete. No temas beber la copa, mira que esta rebosando; no temas ir al Golgota, mira que ahí te esperan tus hijos. Tienes, sin embargo, en San Salvador unos pocos que no han manchado sus vestidos con los ídolos de las bestias. Ellos andarán conmigo vestidos de blanco, porque lo merecen; a ellos les dare la palma del que ha vencido. El que tenga oídos que oiga lo que el Espiritu dice a las iglesias

Universidad Centroamericana José Simeón Cañas 
Al ángcl de la Iglesia de Cuscatlán escribe: Esto dice el Justo, Fiel y Veraz. Conozco la borrascosa situación en que vives, fruto de la injusticia, marginación y explotación. Tus lamentos han llegado hasta mí, las lágrimas vertidas y la sangre de inocentes derramada, por la ayuda letal del norte, conmueve mis enuranas. Apruebo que no distingues entre mano izquierda y derecha para aliviar el dolor. Bendigo tu entereza, puesto en la encrucijada porque nuevamente luzca cl arco iris en tu ciclo, pesc a los nefastos vicntos que soplan de este a oeste. Que las injurias, calumnias y amenazas a muerte no te amilanen, porque yo estoy contigo; mi nombre es tu nombre, me llevas en el corazón y yo te amo. No quedarás defraudado, aun cuando todo esté peor... Pero te advierto, que tu línea profética ha menguado y no valoras la rica herencia que, por la Voz de los sin voz, te he designado; apréciala en su justo valor y verás que es mi mensaje actualizado en el "aquí" y "ahora". Pero tienes buena voluntad y en medio de la prueba no reniegas de tu fc. Jamás te abandonaré y, a su tiempo, convertiré tu tristeza en gozo. Al vencedor le entregaré el galardón, y sabrá el primer mundo que el tercero es fuerte, porque yo lucharé a su lado. El que tcnga oídos, oiga lo que el Espíritu dice a las iglesias.

\section{Notas}

56. Todos los comentarislas destacan que el mismo libro señala una serie de estructuras numéricas que hacen referencia al plan de la obra ( 7 carlas, 7 sellos, 7 trompetas, 7 copas, siendo numerados estos tues últimos septenarios; 3 'ayes', ete.). Por eso se esfuerzan en descubrir la estructura del Apocalipsis. Pues, como señala Prigent op. cit. 364. "el espíritu occidental tiene una conciencia muy viva del carácler revelador del plan de una obra: capiarlo es penetrar en lo más profundo del pensamiento del autor y alcanzar los fundamentos mismos sobre los cuales se eleva el edificio intelectual y literario". Si esto vale para cualquier escrito bßlico, mucho más para los textos apocalípticos. Véase, por ejernplo, para Marcos 13, un texto apocalíptico estructurado concéntricamente, R. Pesch, Naherwartungen. Tradition und Redaktion in Mk 13. Dusseldor 1968; J. Mateos, Marcos 13. El grupo cristiano en la historia, Madrid 1987 (dedica las pp 143-192 a estudiar las posibles estructuras de este capínlo); Gnilka op. cit., 210-211.218.

57. Así Brutsch op. cit., 427 (de lo cual deduce que el orden no es eviderte -lo cual es verdad- ni rígido - lo cual no es tan claro-); Muller op. cir. 30; Charlier op. cir., 423. Sobre los principales estudios sobre la estructura del Apocalipsis, aparecidos hasta el año 1968, puede verse la tesis doctoral de U. Venni, La struftura lesteraria dell Apocalisse, Roma 1971 (y el complemento en su articulo L'Apocalypse 20); también las obras citadas por Prigent op. cit., 364 y el breve informe que da Britsch op. cis., 427-429.

58. Véase una buena síntesis de las principales pistas literarias en Prigent op. eit., 365s. Boismard Apocalipsis I, 141 recoge algunas de las caracterísicas literarias úpicas que han señalado diversos especialistas y que denomina "leyes" (de la inserción, de las ondulaciones, de perpetuidad de las anif́lesis, de periodicidad de la posición de Digitalizado por Biblioteca "P. Florentino ldoate, S.J."

Universidad Centroamericana José Simeón Cañas 
les antútesis). Y Charpentier observa: "También hay que tener en cuenta el procedimiento varias veces utilizado, que podría llamarse del 'papel de calco' (...). Juan nos presenta de buena gana los mismos acontecimientos 'en la tierra' y 'en los cielos'. No se trata entonces de sumar estos hechos como si sucedieran cronologicamente, sino de sobreponerlos para descubrir en la visión 'celestial' el sentido de los acontecimientos humanos. Así, por ejemplo, las siete trompetas pueden muy bien presentas la realización histórica de-aquello que recibe su sentido de los siete sellos" (op. cit. 15). Bogaert op. cit., 136 señala también que "en cada septenario, los seis primeros tiempos son objeto de una descripción, breve para los cuatro primeros, un poco más larga para el quinto, detallada para el sexto. En cuanto al séptimo apunta a un nuevo septenario". Sobre las técnicas de composición del Apocalipsis, véase también E. Schussler-Fiorenza, "Composition and Structure of the Book of Revelation". The Catholic Biblical Quarierly 39 (1977) 359-362.

59. Véase Prigent op. cis., 349; Charlier op. cis., 424.

60. Se discute el número de los septenarios que configuran la estructura del Apocalipsis. Levie (véase Boismard Apocalipsis II, 14ls) propone siete (véase también lo que indica sobre este punto Brulsch op. cif., 427s, notas 3 y 4). Charlier op. cit., 424 (a quien sigo en la estructura gobal del Apocalipsis que propondré) señala cinco septenarios, configurados concéntricamente.

61. Así lo señala Charlier op. cis., 428. Si se tiene en cuenta que las dos últimas visio. nes repiten la fómula kai eidon en el segundo verso de la visión (pero queda claro que con ello no hablan de una visión distinta). los comienzos de las siele visiones hay que situarlos en Ap 19. 11; 19,17;19, 19;20, 1; 20, 4; 20, 11; (y 12) y 21, 1; (y 2).

62. Véase Prigent op. cit., 243ss; también 136ss; Charpentier op. cit., 36s.

63. Por eso no se acepła hoy, sin más, la "teoría de la recapiulación" de Viclorino de Pellau (+304) quien partiendo de la observación acertada de que eslos tres seplenarios centrales no desarrollaban tres serics seguidas de acontecimientos distintos. sacaba la conclusión de que el autor hablaba de los mismos acontecimientos repetidas veces.

64. Con ello el autor nos muestra su voluntad deliberada de excluir toda leclura cronológica de los septenarios (así Prigent op. cir., 130).

65. Véase Müller op. cil., 200. Como nota Prigent op. cil., 149, Ap 10,1-11.14 sc ha de ver como una unidad literaria que ticne como meta que se retarde el cumplimicnto del septenario de las trompetas. Aunque lo llame intermedio o paréntesis (de un modo semejante lo denomina también Müller op. cit., 198), subraya, con razón, que no contiene un mensaje marginal, sino que este fragmento responde a una preocupación primordial del autor. Algunos exegetas (véase Brutsch op. cis., 169) señalan que estos interludios (al igual de lo que ocume en Ap 7: Prigent op. cif., 117 lo denomina un "paréntesis") tienen un tono de consolación en medio de los septenarios de las plagas. Como indica Schissler-Fiorenza Composition, 360, estos "interludios" expresan la relación entre la realidad presente y el futuro cscatologico.

66. Véase más abajo cuando expliquemos el sentido del septenario de las cartas y la nota 73.

67. Vease Charlier op. cis., 425ss. Aunque con variantes, para la estrucura me inspiro sobre todo en la estructura concénurica que propone Charlier. porque es la que mejor se corresponde con los datos que proporciona el Apocaljpsis. Las estructuras Digitalizado por Biblioteca "P. Florentino Idoate, S.J."

Universidad Centroamericana José Simeón Cañas 
concéntricas, por otro lado, son frecuentes en el Nuevo Testamento (por ejemplo es ya clásica la estructura coneéntrica que A. Vanhoye ha propuesto para la carta a los Hebreos: El mensaje de la caria a los Hebreos, Estella 1978, pp. 30-34).

68. Véase nota anterior. Para otras estructuras, véase la bibliografía citada en la nota 57. Una estructura clásica es la que divide la obra así (véase por ejemplo Charpentiet op. cis., 16-17): Ap 1-3, Introducción (Chapentier la califica como "una Iglesia muy humana"); Ap 4-11. Primera parte (Ch. dice que aquí se enfrenta con el problema del paso de Israel a los paganos); Ap 12-20, Segunda parte (Ch.: la Iglesia ante los poderes totalitarios); Ap 21-22, Conclusion (Ch. una Iglesia "bajada del cielo"): véase Varios Marla; 215s, pero en la p. 216 nota 9 se confiesa que el fundamento de esta división es inciet to y se añade: "en cualquier esquema del Apocalipsis ha de reconocerse que los patrones numéricos de la segunda parte son menos precisos que los de la primera parte". Creo que en la estructura que proponemos no es así. Y, en todo caso, una estructura que subraya el problema del paso de Israel a los paganos no me parece acertada, pues no es un problema que parezca preocupar especialmente al Apocalipsis (contra Charpentier que afjma a propósito de Ap 4-11: "En esta primera sección, Juan nos muestra que Israel ha sido sustituído por la Iglesia. Pero el antiguo Israel no ha sido rexhazado pura y simplemente, ya que el 'resto' $\longrightarrow$ sea aquellos que, en Israel, son verdaderamente fieles a Dios y han reconocido a Jesús- se ha convertido en el punto de partida de la Iglesia. La Iglesia ha nacido del judaŕsmo, pero para abrirse a los paganos" (op. cir., 22).

69. Véase Vanni L'Apocalypse, 26, nota 18. La estructura que propongo cteo que orilla esta dificultad. Tiene la ventaja de que combina los elementos literarios y tcoló. gicos (responde a la exigencia de combinar los dos elementos, tal como pedía Vanni. La strustura, 1-3). Por eso Schussler-Fiorenza, Composision, 360, califica la estructura del Apocalipsis como una "espiral cónica" que se mueve desde la visión de la entronización del Cordero hesta la venida de Cristo en la Parusía.

70. Según Prigent op. cir., 36s, el aubr (todo el mundo está de acuerdo en que cl estilo de las cartas no es distinto del que encontramos en el resto del Apocalipsis) habría compuesto las cartas cuando ya había escrito el resto de la obra pues las imágenes de Cristo sólo se iluminan a la luz del resto del Apocalipsis (pero se podría objetar que si el autor tenía claro lo que quería decir. no necesitaba eñadir el texto tan sólo en una segunda edición). Véase también Boismard Apocalipsis II 143 (habrían sido ariadidas junto con Ap 1, 11-18 que prepara la introducción de las cartas); H. Kraft, Die Offenbarung des Johannes, Tubinga 1974, pp. 14s. 50; González Ruiz op. cis., 87s. En cambio Strobel op. cit., 178, dice que no hay argumentos convincentes que prueben que las cartas fueron añadidas posteriormente. Según Prigent op. cii., 372 la existencia también de dos epnlogos de la obra (Ap 22, 6ss y 22, 16ss) confirmaría que las cartas habrian sido añadidas en una segunda edición que intentaría aplicar a una nueva situación, bien conctela, el mensaje primitivo de la obra. Pero SchulsslerFiorenza, Composition, 362, nota, con razón, que a traves del modelo del "septenerio" y de lasrelaciones literarias coneretas, Juan ha unido este septenario al resto de la obra.

71. Así Muller op. cit., 29 (y la hipótesis se basa en suposiciones no probadas).

72. Op. cit., 425. Por otro lado conviene notar que, como indica Prigent op. cil., 80, Jas cartas pretenden luchar contra un peligro bien concreto: "un dualismo de inspira-
Digitalizado por Biblioteca

Universidad Centroamericana José Simeón Cañas 
eión gnóstica relativiza la noción de fidelidad cristiana y rechaza la necesidad de una obediencia intransigente hasta a rontar la muerte".

73. Sobre el significado de las cartas en el Apocalipsis, véase Prigent op. cit., 36-80. La estruerura concéntrica y progresiva de las cartas, que ofrecen una estnuctura claramente csleteolipada, la presenta muy bien Vanhoye op. cit., $32 \mathrm{~s}$.

74. Según Charlier op. cit., 426 en él se establece una especie de balance del mundo. En cambio Prigent op. cit., 94 s (seguido por González Ruiz op. cit., 115) cree que cl libro es el Antiguo Testamento que resulta letra muerta mientras Cristo no lo ilumina (y cita en este sentido las opiniones de Hipólito, Orígenes. Victorino de Pettau), aunque scĩala que muchos autores ven en el libro "cl plan de Dios" (lo que sucederá). Véase diversas opiniones en Brutsch op. cir., $106 \mathrm{s.}$

75. Si el libro está cscrito según Ap 5, 1 por el anverso y el reverso (el autor piensa en un rollo que cstá enrollado), apenas se puede leer nada de él.

76. Sobre el concepto negativo de mundo en Juan, véase J. Mateos-J. Barreto, Vocabulario teológico del Evangelio de Juan, Madrid 1980, 213-215.

77. Prigen op. cil., 369-371 ha subrayado acertadamente el talante joánico del Apocalipsis. Véase también Boismard Apocalipsis 164s; Gonź́lez Ruiz op. cit., 54-60. En cambio, Múller al tratar la cuestión del autor del Apocalipsis, cree que no hay que hablas del "jumismo" del Apocalipsis, como si perteneciera a un "círculo joánico" (sostiene, a mi juicio, sin razón, que el autor pertenece a un círculo judeocristiano siro-palestino): véase op. cir., 43-52.

78. Véase antes nota 65.

79. Sobrc el significado del libro y de Apocalipsis 10, véase Prigent op. ril.. 150-156; Britsch op. cil., 168-176. González. Ruiz op. cit., 138 (sigue a Fcuillet) cree que cl libro se relicre al Nuevo Testamento, pero que es mejor traducirlo por "codicilo" y que se refiere a lo que el autor va a ofrecer en los capítulos siguientes.

80. Medir puede tencr distintos significados, pero aquí significa claramente proteger (véase Müller op. cif., 206). El Templo y la Ciudad Santa se refieren a la Iglesia, de「inida, simbólicanente, como Templo preservado y como atrio entregado a los paganos (así Prigent op. cit., 161-163). Cerfaux-Cambier op. cil., 112, lo comenta así: "Nosolros los cristiaros, somos el pucblo de Dios intangible, ese templo espiritual al que San Juan ha medido. Pero seguimos comprometidos en el mundo presentc, ese atrio exterior que van a hollar Jos paganos", pues como dice Charpentier op. cis., 42, "Juan manifiesta de este modo la situación especial de la Iglesia en el curso de la historia; abandonada por Dios en manos de sus enemigos, pero protegida interiomente, como sej̃ala la siguiente visión (Ap 12, 13-18)", véase también Müller op. cif., 207s. Por eso Prigent (en el lugar citado antes) no acepta. con razón, la interpretación bastante extendida de que el Templo se refiere a los judíos que sc convicrten al cristianismo, pues el problema judío no parece interesar especialmente al autor y no se puede referir sólo a Israel lo que Juan refiere al testimonio cristiano en el mundo pagano. Sobre las interpictaciones de Ap 11, 1s, véase Britsch op. cis., 179-182, y Müller op. cit., 205ss, quien señala que Apocalipsis 11 es uno de los textos más oscuros del Apocalipsis. Los 42 meses ó 1260 días (véase también Dn 7. $25 ; 12,7)$ caracterizan el tiempo presente de la Iglesia, que es el tiempo de la fidelidad amenazada o de la profecía perseguida (véase Prigent op. cit., 158), el tiempo pascual que está bajo el signo de la protección divina y de las amenazas salánicas (asi Prigent op. cil., 191; también 176s y 305). Como nota Swecl op. ril.. Digitalizado por Biblioteca "P. Florentino Idoate, S.J."

Universidad Centroamericana José Simeón Cañas 
183, Juan está urgiendo a su Iglesia el que vea toda su vida y obra bajo el signo del "res y medio" que abarca los aspectos de la invulnerabilidad (11, 3-6) y del eclipse $(11,7-9 ; 13,5-7)$, pues ambos pertenecen a la esencia de la Iglesia.

81. Prigent op. ciu., 149s nota que la punta de Ap 10,1-11, 14 es señalar el lugar que ocupa en la escatología el ministerio de los profetas. Mullet op. cis., 210, (véase también 210-217) señala, con razón, que con los dos profelas Juan no cstá pensando en dos personas concretas, sino en los predicadores proféticos de la Iglesia (ibid. 211), pues "la alımmación del v. 4 sólo se puede entender desde el trasfondo del resto de las afirmaciones del autor. Los candelabros son para él inagen de las comunidades cristianas $(1,20 ; 2,5)$, de modo que los dos testigos simbolizan la comunidad cristiana y, por cierb, con vistas a sus predicadores proléticos, tal como lo muestra el encargo de 'profetizar, predecir' (v. 3)" (ibid., 210). También Cerfaux-Cambier (op. cil., 118) insisten en que se refieren a la Iglesia (o los márlires, ibid., 114s). Según Rissi op. eit., 114, los dos olivos se refieren a la comunidad que es vista, al igual que en Zacarias 4, 2-14, como sacerdotal y real (véase Ap 1, 6; $5,10)$. Zacarías tiene un solo candelabro. Pero como en los dos testigos se expresa la misma realidad, por eso hay que duplicarlos. Rissi ve tepresentados en ellos una comunidad que procede de Isreel y de los pagaros, mientras que Brütsch que anali. za el significado de Ap 11, 3-13, en op. cis., 183-190, se inclina - a mi juicio sin razón- por ver en los dos testigos la imagen de los judeocristianos (ibid.,184, nota 5).

82. Así, Prigent op. cil., 166 (véase ibid. 164s). Si Juan cuenta la muerte de los profetas a imagen de la crucifixión y resurrección-exaltación de Cristo, es para mostrar la importancia que tiene para el discípulo imitar al maestro (ibid., 168). También Gonzílez Ruiz op. cit., 143 nota a este propósito que "la historia de la Iglesia será una sucesión de profetismo muerto y resuciado"; véase también Charpentier op. cit., 9. que se basa en Feuillet ("La moisson et la vendage de l'Apocalypse". Nouvelle Revue Theologique 94 (1972) 240). Algunos han pensado, sin fundamenம, en el testimonio de Pedro y Pablo (véase la crílica en Muller op. cit., 210s; Prigent op. cis., 165).

83. Véase Prigent op. cil., 149s. "Uno no espera pasivamente, el minislerio de los profetas contribuye al acabamiento final" (ibid. 152), pues la séplima trompeta no sonará mientras la Iglesia no haya cumplido con su vocación de ser aquí testigo de Jesús (lbid., 164).

84. Según Bogaert op. cil., 136, "hay buenas razones para creer que el sexlo ticmpo se refiere a acontecimientos de los cuales el autor es o quiere ser contemporáneo. Y es posible mostrar que la sexta trompeta, el sexto sello y la sexta copa recuerdan la Guerra Judía". Como hemos visto antes en la nota 80, el tiempo del "tres y medio" (ó 42 meses 61260 días) es el tiempo que está viviendo ahora la Iglesia.

85. Véase Gn 37, 9-11. Sobre la simbología veterotestamentaria de Ap 12, véase Prigent op. cif., 180-182. Sobre el significado de la mujer, véase lo dicho antes en las notas 48 y 49 . A la bibliografía allf indicada, se puede añadir Múller op. cis., 231 (véase 228-231), quien defiende umbién que la mujer encama el verdadero Israel, el pueblo de Dios de la antigua y de la nueva Alienza. Sobre la abundante literatura que ha provocado este capímlo y la variedad de opiniones, puede verse Britsch op. cit., 198-218. 
86. Véase lo que hemos dicho en la nota 49. Véase también Prigent op. cis., 191-193. Según Charpentier op. cil., 27, "lodo queda claro (...) si se ve en este 'nacimiento" la entronización de Jesús como mesías glorificado en su resurnección". Salanás "pensó haberlo 'devorado' en la cruz, pero, al glorificar a su Hijo, Dios destruyó su aparente victoria"; véase también Comblin op. cit., 259; Rissi op. cir., 126.

87. Op. cis., 27. Como se indica en Varios María, 222, "el motivo de la mujer en el desierto, de Ap 12, 6.14 tiene como probable destino recordar a Israel y el ćxodo. La historia del éxodo demuesta ciertamente cómo ha protegido Dios a Israel en el desierto, y aun le ha alimentado en él (cf. Ap 12,14 y Ex 16, 4-17); la mujer transportada por 'las alas del águila grande' (Ap 12,14) recuerda las palabras de Dios a la casa de Jacob/Israel en Ex 19, 4: 'Te he llevado sobre alas de águna' (asimismo Dt 32, 11-12)"; véase también Sweet op. cis., 203 s.

88. Véase Alegre Mi Reino, 507.509 y la bibliografía allí indicada. El aspecto de la derrota fundamental de Satanás, como consecuencia de la exaltación de Jesús, la explica el Apocalipsis a continuación en 12.7-12. Ello no quila que detrás de la lucha entre Miguel y Salán pueda estar el mito judío de la caída de los ángeles del cielo (véase Gn 6, 1-4; 1Hen 6-19; Jubilcos 5; Vida de Adán y Eva 12-17) (véasc 12-17 y Varios María, 220s).

89. Véase antes nota 4. Véase también Müller op. cif., 253-256 y su excurso sobre el culto al emperador romano, con la bibliografía allí indicada (ibid., 257-260) y Brutsch op. cit., 227-231.

90. Véase Prigent op. cir., 199 y 209. Según Chapentier op. cit., 28, la bestia de la lierra representa la ideología de la época (y de todas las épocas).

91. Véase Prigent op. cis., 243-251.

92. Detrás del símbolo está la imagen de la "copa de la ira de Yahvéh", clásico en el profetismo (véase Is $51,17.22 ; \mathrm{J}_{\mathrm{r}} 13,13 ; 25,15-17 ; 48,26 ;$ Ez. 23, 32-34; Hab 2. $15 \mathrm{~s}$, etc.).

93. Modelo de la lamentación es Ez 27-28 (a propósito de Tiro). En este capírulo resuena la crítica profética al lujo y a la injusticia de los habitantes de la tierra (es decir, los incrédulos), los reyes y los comerciantes, que son vistos ahora como aliados del imperio romano (véase Schüssler Fiorenza Redemplion 230). La crílica social del autor del Apocalipsis es subrayada tambićn por U. Vanni a propósito de Ap 6. 5s, cuando, despućs de tratar el texto de Ap 18, concluye: "El consumismo instrumentaliza también la vida humana, expresando así el máximo de injusticia social" ("II terzo sigillo dell'Apocalisse (Ap 6, 5-6): simbolo dell'ingiustizia sociale?". Gregorianum 59 (1978) 716. véase 691-718).

94. Como puede verse en distinios autores del Nuevo Testamento (véase la utilización de Is 6, 9s en Mc 4, 12s; Mt 13, 14s; Le 8, 10; Hech 28, 25.27; Jn 12, 40s; véase también cómo Pablo trata el problema en Rm 9.11), la incredulidad del pueblo judío y del mundo, en general, cres un problema serio a las primeras comunidades. que intentan resolver teológicamente el problema recuriendo al Antiguo Testamento.

95. Véase P. Ricoeur, "La logique de Jésus. Romains 5," Études Théologiques et Religieuses 55 (1980) 420-424 (condensado un Selecciones de Teología 21 (1982) 130-132). Es la "lógica" que Jesús quería para su Iglesia (véase X. Alegre, "La Iglesia que Jesús quería". Diakonía (Nicaragua) 13 (1989) 223-268, también en: Varios, Iglesia ide donde vienes y a dínde vas?. Barcelona 1989, pP. 19-52.

Universidad Centroamericana José Simeón Cañas 
96. Así Prigent op. rii., 234s. Charpentier (que sigue a Feuillet) comenta: "mientras que el cuadro de la cosecha se aplica a todos los fieles cristianos, el de la vendimia sólo se aplica a los mártires" (pero me parece más acertada la opinión de Prigent).

97. Además de formar inclusión con el primer sepıenario, que habla de la Iglesia mililante (mosuando cómo se pasa de ésta a la Iglesia triunfante: todo ello se explica en la parle central de la obra), hay también una referencia entre la primera visión de este septenario y la apertura del primer sello del segundo septenario. La cuarta visión - la central- se relaciona también con el septenario central que habla del establecimicnto del reino de Dios en la tierra (en relación con la exaltación de Jesús y con la derrola definitiva del mal que se narra en la quinta visión).

98. Como indica Prigent op. cit., 304, los textos, tanto del judaísmo, como del cristianismo primitivo que ratan de la duración del reino mesiánico, hablan de una duración signifjcativa. Por ejemplo, la estancia en el paraíso, euyo retomo anuncia Is 65 , 22, se cree que duró 1000 años. Pues Dios dijo a Adán en Gn 2, 27 que moriría el día mismo en que comiera del fruto prohibido. Si un día del Señor es como 1000 años (S] 90, 4), se comprende que según Gn 5, 5 muriera Adán a los 930 años. Por eso los cristianos pensaban que la estancia en el paraíso instaurado por el Mesías duraría mil años (véase en Prigent los textos cilados por él). Por eso Prigent (ibid.) saca la conclusión de que el reino de mil años significa, en lenguaje simbólico, que se restauran las condiciones de la vida paradisíaca perdidas con la caída. La obra de Cristo comporta el fin del poder de la serpiente (Ap 12, 9; 20, 3) y se puede ofrecer el árbol de la vida a los que, con Cristo, son vencedores de Satán (Ap 2, 7; 22. 14.19). Los fieles pueden entrar ya en el jardĺn de Dios y vivir una vida resucitada, sin temor a la muerte. Reinan ya con Cristo y participan en el juicio y la victoria. Sobre las distintas interpretaciones del milenio a lo largo de la historia de la Iglesia, véase Prigent op. cit., 300s; Boismard Apocalipsis II 152-155; Brüssch op. cit., 320 . 335.

99. A la objeción de cómo se puede alurmar en un mundo tan injusto que Satanás ya está ligado, responde Prigent op. cis., 303s que no hay que olvidar la parábola evangélica del hombre fuerte atado por Cristo (Mt 12, 29; Mc 3, 17; Lc 11, 21). En estas visiones, la segunda muerte se refiere a la perdición eterna, mientras que la primera muerte es la muerte lísica (véase Prigent op. cir., 303). En cuanto a la primera resurtección ( $i e l$ Apocalipsis no habla de una segunda!), significa, de acuerdo con la escatologla de presente propia de las comunidades juánicas, que los ficles gozan ya aquí y ahora de la vida eterna y que, por tanto, no deben temer la muerte (Jn 5,$25 ; 11,25 \mathrm{~s}$ ): véase Prigent 303.306.311s. No creo que tengan razón Cerfaux-Cambier op. cil., 211 cuando afíman "la 'primera resurrección' está reservada a los que han dado lestimonio; y precede a la resurtección general (...) es el privilegio de los mártires y de los perseguidos".

100. También el primer septenario estaba estruchurado concéntricamente, aunque de otra manera.

101. Así se distancia Juan de las expectativas judías de la apocalíptica contemporánea (véase por ejemplo 4Esdras 7,28s; 2 Baruc 29, 1ss). Para ellos, será una época paradisíaca: "También la tierra dará fruto, diez mil por uno. Cada cepa tendrá mil sarmientos, cada samiento dará mil racimos, cada racimo contará mil uvas y cada uva producirá un kor (30 litros) de vino. Y lodos los que tengan hambre se alegrarán y serán cada día espectadores de prodigios. Los vientos emanarán de mi rostro

Digitalizado por Biblioteca "P. Florentino Idoate, S.J."

Universidad Centroamericana José Simeón Cañas 
para llenar cada día de perfume frutos aromáticos y suscitar a la caída de la tarde nubes que destilen un rocío saludable. En aquel tiempo, el maná guardado en reserva caerá de nuevo y comerán (de él) esos años, porque habrán llegado al fin de los tiempos" (Bar sir o 2Bar 29, 5-8). "Entonces serán humildes todos los justos, vivirán hasta engendrar a mil hijos y cumplirán en paz lodos los días de su mocedad y vejez. En csos días, toda la tierra será labrada con justicia; loda ella quedará cuajada de árboles y será llena de bendición. Plantarán en ella toda clase de árboles amenos y vides y la parra que se plante en ella dará fruto en abundancia. De cuanta semilla sea plantada en clla, una medida producirá mil, y cada medida de aceitunas producirá diez. tinajas de aceite" (1Hen 10, 17-19). Véase Brütsch op. cis., 323s.

102. Véase Ez 38, 4ss. 18.20. Ap 19, 17-21 se inspira en la profecía de la derrola de Gog en Ez 38-39 (la batalla contra los reyes había resonado ya en Ap 16, 14ss y 17, 14). Sobre el significado véase Prigent op. cis., 297s.

103. Grandes y pequeños aparecen lambién en Ap 11,$18 ; 13,16 ; 19,5$.

104. Sobre los rasgos que, según se puede deducir de los evangelios, debía lener la Iglesia "que Jesús quería", véase mi artículo cilado en la nola 95. 